\title{
Cancer-Associated Substitutions in RNA Recognition Motifs of PUF60 and U2AF65 Reveal Residues Required for Correct Folding and $3^{\prime}$ Splice-Site Selection
}

\author{
Jana Kralovicova ${ }^{1,2,+}$, Ivana Borovska ${ }^{2,+}$, Monika Kubickova ${ }^{3}$ D, Peter J. Lukavsky ${ }^{3}$ (D) \\ and Igor Vorechovsky ${ }^{1, *(D)}$ \\ 1 Faculty of Medicine, University of Southampton, Southampton SO16 6YD, UK; jakr@soton.ac.uk \\ 2 Institute of Molecular Physiology and Genetics, Center of Biosciences, Slovak Academy of Sciences, \\ 84005 Bratislava, Slovakia; ivana.sevcikova@savba.sk \\ 3 CEITEC, Masaryk University, 62500 Brno, Czech Republic; monika.kubickova@ceitec.muni.cz (M.K.); \\ lukavsky@ceitec.muni.cz (P.J.L.) \\ * Correspondence: igvo@soton.ac.uk; Tel.: +44-2381-206425; Fax: +44-2381-204264 \\ + These authors contributed equally to this work.
}

Received: 15 June 2020; Accepted: 7 July 2020; Published: 11 July 2020

\begin{abstract}
U2AF65 (U2AF2) and PUF60 (PUF60) are splicing factors important for recruitment of the U2 small nuclear ribonucleoprotein to lariat branch points and selection of $3^{\prime}$ splice sites ( $\left.3^{\prime} \mathrm{ss}\right)$. Both proteins preferentially bind uridine-rich sequences upstream of $3^{\prime}$ ss via their RNA recognition motifs (RRMs). Here, we examined 36 RRM substitutions reported in cancer patients to identify variants that alter 3'ss selection, RNA binding and protein properties. Employing PUF60- and U2AF65-dependent 3'ss previously identified by RNA-seq of depleted cells, we found that $43 \%$ $(10 / 23)$ and $15 \%(2 / 13)$ of independent RRM mutations in U2AF65 and PUF60, respectively, conferred splicing defects. At least three RRM mutations increased skipping of internal $U 2 A F 2(\sim 9 \%, 2 / 23)$ or PUF60 $(\sim 8 \%, 1 / 13)$ exons, indicating that cancer-associated RRM mutations can have both cis- and trans-acting effects on splicing. We also report residues required for correct folding/stability of each protein and map functional RRM substitutions on to existing high-resolution structures of U2AF65 and PUF60. These results identify new RRM residues critical for 3'ss selection and provide relatively simple tools to detect clonal RRM mutations that enhance the mRNA isoform diversity.
\end{abstract}

Keywords: Functional genomics; pre-mRNA splicing; $3^{\prime}$ splice site; mRNA; lariat branch point; PUF60; U2AF2; SF3B4; gel shift assay; differential scanning fluorimetry; cancer; leukemia; driver mutation; exon inclusion

\section{Introduction}

Next-generation sequencing studies of cancer cells have identified mutations affecting important protein domains in RNA processing factors involved in $3^{\prime}$ splice site $\left(3^{\prime}\right.$ ss) selection, first described in myelodysplasias [1]. In several genes, most notably SF3B1 (also known as SF3b155) and U2AF1 (U2AF35), the mutations are restricted to missense variants that encode just a few amino acids [1-3]. These alterations can directly impair contacts with precursor messenger RNAs (pre-mRNAs), as exemplified by substitutions in U2AF35 zinc-finger domains [4], or may act indirectly. For example, cancer-associated mutations in the HEAT domains of SF3B1 [1] were proposed to lead to changes in the positioning of other RNA-binding proteins, including the 65 kilodalton $(\mathrm{kD})$ subunit of the $\mathrm{U} 2$ small nuclear ribonucleoprotein auxiliary factor (U2AF65), ultimately altering interactions with 
pre-mRNAs [5] and the selection of lariat branch points and 3'ss [6-8]. Apart from SF3B1 and U2AF1, clonal mutations have been found in genes encoding other $3^{\prime}$ ss recognition factors, including U2AF2 and PUF60, but at lower frequencies [1,9]. The two proteins bind highly variable and uridine-rich 3 'ss consensus motifs known as the polypyrimidine tracts (PPTs), cooperatively recruiting the U2 small nuclear ribonucleoprotein by simultaneously binding to SF3b155 [10-14]. U2AF2 and PUF60 mutations in cancer cells are less restricted than those in SF3B1 or U2AF1 [1]; nevertheless, a previous study mapped recurrent mutations to U2AF65-RNA interfaces [15]. However, the functional fraction of PUF60/U2AF65 mutations in their RNA recognition motifs (RRMs) is unknown and their impact on protein properties and cancer initiation is not fully understood.

RRM-containing proteins make use of sophisticated strategies to interact with a large repertoire of single-stranded sequences with a considerable range of affinities [16]. Both U2AF65 and PUF60 preferentially bind uridine (U)-rich RNA sequences at PPTs via their RRMs to recruit U2 small nuclear ribonucleoprotein particles to the branch site $[10,11,14,17,18]$. Both U2AF65 and PUF60 contain central tandem RRMs and C-terminal U2AF-homology domains (UHMs), but PUF60 lacks the N-terminal arginine/serine-rich (RS) domain and the UHM-ligand motif (ULM) [10,12,18]. Through global identification of PUF60-regulated exons, we have recently characterized splicing abnormalities in cells overexpressing PUF60 that contained germ-line RRM missense mutations [14] found in Verheij syndrome (also known as or PUF60 deficiency, PD, or 8q24.3 microdeletion syndrome) $[19,20]$. Interestingly, PD-associated RRM substitutions generated a spectrum of splicing defects that could be seen with single tested exons [14]. PUF60 is required for cell viability, proliferation and migration in vitro and is often overexpressed in (pre-)malignant tissues [21,22], suggesting that the heterogeneity of missense RRM mutations in cancer cells might influence 3'ss/branch site recognition and expand mRNA isoform diversity. Nevertheless, this hypothesis has not been systematically tested and functional RRM substitutions remain unidentified.

In the present study, we employed PUF60- and/or U2AF65-dependent splicing reporters and biochemical assays to discover cancer-associated missense mutations in PUF60 and U2AF65 RRMs that impair protein function. We have found that RRM substitutions can cause splicing defects of their target 3'ss (trans) or their own transcripts (cis), which may further enhance the mRNA diversity of cancer cells. We also identified cancer substitutions that altered protein folding/stability and reduced RNA binding to multiple $3^{\prime}$ ss in vitro. These results validate new and relatively simple tools for the detection of functional U2AF65 and PUF60 substitutions and reveal strong clonal candidates that may drive cancer initiation or progression. They should also facilitate the design of structure-guided RRM variants that could selectively alleviate splicing defects in cancer cells.

\section{Materials and Methods}

\subsection{Plasmid Preparations}

Plasmid pET28a-PUF60-His for expression of human PUF60 (transcript ENST00000526683) in E. coli was described previously [23]. PUF60 was subcloned into BamHI/XhoI sites of pcDNA3.1/myc-His A (Invitrogen) in-frame with the myc tag at the C-terminus. The WT U2AF65 (a generous gift of Professor Andrew Berglund, University at Albany, New York, NY, USA) was subcloned into the same vector using BamHI/XhoI digests.

Conserved missense RRM1 and RRM2 mutations for testing were selected from the highly curated and publicly available catalogue of somatic mutations in cancer (COSMIC) database (v.83) [9]. Mutated PUF60 and U2AF65 plasmids were prepared by overlap extension PCR using mutagenic primers shown in Table S1. PCR products were digested with BamHI/XhoI and ligated into pcDNA3.1/myc-His A using a T4 DNA ligase (Promega). Minigenes for testing inclusion levels of U2AF2 and PUF60 exons with RRM mutations were prepared using primers listed in Table S2. Sequences of all reporters are shown in Figure S1. All plasmids were propagated in E. coli DH5 $\alpha$; plasmid DNA was extracted using the GeneJET Plasmid Miniprep Kit (Thermo Fisher, Waltham, MA, USA). Constructs were 
validated by Sanger sequencing. Each construct lacked undesired mutations, except for U2AF65 G326E, which contained an extra missense mutation in the same RRM.

\subsection{Cell Cultures and Transfections}

Validated plasmid DNA (200 ng) was transiently co-transfected with the reporter plasmid (80 ng) and $30 \mathrm{ng}$ of the pcDNA3.1-EGFP into human embryonal kidney (HEK) 293 cells obtained from the Leibniz-Institute DSMZ-German Collection of Microorganisms and Cell Cultures (cat. ACC305). Transfections were carried out in 24-well plates using jetPRIME (Polyplus) according to manufacturer's recommendations. Cells were harvested $48 \mathrm{~h}$ after transfection for RNA and protein preparations. PUF60 depletion was performed as described previously [14].

\subsection{Detection of Spliced Products}

Total RNA was extracted using TRI-reagent (Ambion, Austin, TX, USA), treated with DNase I (Promega, Chilworth, UK) and transcribed using the Moloney murine leukaemia virus (MMLV) reverse transcriptase (RT, Promega) and primer $\mathrm{d}(\mathrm{T})_{20}$ according to the manufacturers' recommendations. RT-PCR reactions were performed using vector-specific primers or a gene- and vector-specific combination (Table S2), as described previously in detail [14,24,25]. Uncut OGDH products were amplified with primers PL4 and 35F, whereas OGDH products digested with Hinfl, which cut only exon $4 \mathrm{~b}$, were amplified with primers PL4 and 35m-amplF (Table S2). RT-PCR amplifications were for 29 cycles to maintain approximately linear relationship between the RNA input and output signals. PCR products were separated on agarose or polyacrylamide gels and stained with GelRed (Biotium, Fremont, CA, USA). Signal intensity of the spliced products was measured as described [26].

\subsection{Utilization of Cryptic 3'ss of UBE2F Exon 5 in Human Endogenous Transcripts}

We employed a panel of total RNAs isolated from human tissues, each containing a pool from several different donors (FirstChoice; Life Technologies, Carlsbad, CA, USA). The first strand cDNAs were prepared using $\mathrm{d}(\mathrm{T})_{20}$ and MMLV RT. RT-PCR reactions were carried out with primers UBE2F-cr and UBE2F-R or UBE2F-F and UBE2F-R (Table S2). Apart from the cryptic 3'ss of exon 5, the former pair also amplified a cryptic exon in intron 4 in a tissue-specific manner. The identity of each RNA product was confirmed by Sanger sequencing.

\subsection{Immunoblotting}

Cells were washed with PBS and lysed in the RIPA buffer $(150 \mathrm{mM} \mathrm{NaCl}, 1 \%$ NP-40, 0.5\% deoxycholate, $0.1 \%$ SDS, $50 \mathrm{mM}$ Tris, $\mathrm{pH}$ 8.0). Protein lysates were loaded onto $10 \%$ SDS-PAGE, transferred on to nitrocellulose membranes and incubated with antibodies against c-myc (PLA0001, Sigma), GFP (ab290, Abcam) and the His tag (ab1187-100, Abcam). Secondary antibodies were purchased from Thermo Fisher (\#31458). Proteins were detected using the Pierce ECL Western Blotting Substrate (Thermo Fisher) according to the manufacturer's instructions.

\subsection{Protein Expression and Purification}

Constructs for the expression of recombinant WT and mutated PUF60 were created by inserting validated BamHI/XhoI fragments into the pET-28 vector with $2 \times$ His-lipoyl-TEV site. The proteins were expressed in BL21-CodonPlus (DE3)-RIL competent cells (Agilent Technologies). The cells were grown to OD 0.8 at $37^{\circ} \mathrm{C}$. Protein expression was induced with $1 \mathrm{mM}$ IPTG overnight at $16{ }^{\circ} \mathrm{C}$. Cell pellets were dissolved in a $1 \mathrm{M} \mathrm{NaCl}, 20 \mathrm{mM}$ HEPES, $\mathrm{pH} 7.5,10 \%$ glycerol (w/v), $30 \mathrm{mM}$ imidazole and $3.6 \mathrm{mM} \beta$-mercaptoethanol buffer containing the cOmplete ${ }^{\mathrm{TM}}$, an EDTA-free Protease Inhibitor Cocktail (Roche), and were lysed using EmulsiFlex-C3 (Avestin Europe GmbH). After centrifugation, the supernatants were loaded onto the $\mathrm{Ni}^{2+}$-charged HiTrap IMAC HP columns (GE Healthcare Life Sciences) through $0.45 \mathrm{~mm}$ filters and eluted in a buffer containing $0.5 \mathrm{M} \mathrm{NaCl}, 20 \mathrm{mM} \mathrm{HEPES} \mathrm{(pH} \mathrm{7.5),}$ $10 \%$ glycerol $(\mathrm{w} / \mathrm{v}), 300 \mathrm{mM}$ imidazole and $3.6 \mathrm{mM} \beta$-mercaptoethanol. His-tags were removed by overnight cleavage with the in-house TEV protease in a buffer containing $500 \mathrm{mM} \mathrm{NaCl}, 20 \mathrm{mM} \mathrm{HEPES}$, $10 \%$ glycerol $(\mathrm{w} / \mathrm{v})$ and $3.6 \mathrm{mM} \beta$-mercaptoethanol. The TEV protease was removed using the charged 
HiTrap IMAC HP column. For long-term storage, proteins were dialyzed against a $50 \mathrm{mM}$ potassium phosphate buffer ( $\mathrm{pH}$ 6.8) containing $300 \mathrm{mM} \mathrm{NaCl}, 10 \%$ glycerol $(\mathrm{w} / \mathrm{v})$ and $3.6 \mathrm{mM} \beta$-mercaptoethanol, freezed in liquid nitrogen and stored at $-80^{\circ} \mathrm{C}$.

U2AF65 was expressed as a GST fusion protein using pGEX6P-U2AF65 (a generous gift of Professor Andrew Berglund). Mutated plasmids carrying G154V, E162K, E207G and G319V were prepared by inserting BamHI/XhoI fragments into pGEX6P-GST and were again validated by sequencing. The recombinant U2AF65 proteins were produced in BL21 (DE3) pLysS competent cells (Promega). Cells were grown at $37^{\circ} \mathrm{C}$; protein expression was induced with $1 \mathrm{mM}$ IPTG. The pellets were dissolved in $50 \mathrm{mM}$ Tris- $\mathrm{HCl}$ ( $\mathrm{pH} 8.0), 200 \mathrm{mM} \mathrm{NaCl}, 1 \mathrm{mM}$ EDTA and $1 \mathrm{mM}$ DTT containing cOmplete $^{\mathrm{TM}}$, an EDTA-free Protease Inhibitor Cocktail (Roche, Basel, Switzerland), and were sonicated using SONOPULS GM Mini20 (Bandelin Electronic, Berlin, Germany). The recombinant proteins were purified from supernatant using Glutathione Sepharose ${ }^{\circledR} 4$ Fast Flow (GE Healthcare, Chicago, IL, USA), washed four times with PBS and eluted in $50 \mathrm{mM}$ Tris- $\mathrm{HCl}$ (pH 8.0), containing $20 \mathrm{mM}$ reduced glutathione. Purified proteins were dialyzed against $25 \mathrm{mM}$ Tris- $\mathrm{HCl}(\mathrm{pH} 7.5), 300 \mathrm{mM} \mathrm{NaCl}$, 15\% glycerol (w/v), 1 mM DTT, using Slide-A-Lyzer ${ }^{\mathrm{TM}} \mathrm{G} 2$ Dialysis Cassettes (Thermo Fisher).

\subsection{Electrophoretic Mobility Shift Assay (EMSA)}

Gel shift assays were carried out essentially as described [23], but with biotinylated RNAs (Table 1). Briefly, WT and mutated proteins were incubated with the indicated oligoribonucleotides in a binding buffer containing $5 \mathrm{mM} \mathrm{MgCl} 2,0.25 \mu \mathrm{g} / \mu \mathrm{L}$ heparin, $40 \mathrm{mM}$ Tris ( $\mathrm{pH}$ 8.0), $0.01 \%$ Triton and $1 \mathrm{mM}$ DTT at room temperature for $20 \mathrm{~min}$. RNA/protein complexes were separated on $6 \%$ native polyacrylamide gels run in $0.5 \times \mathrm{TBE}$ at $4{ }^{\circ} \mathrm{C}$, blotted onto nylon membranes (GE Healthcare) and crosslinked on a 254-nm UV transilluminator for $60 \mathrm{~s}$. The products were detected with LightShift ${ }^{\circledR}$ Chemiluminescent EMSA Kit (Thermo Fisher) according to manufacturer's recommendations. Signal intensity was measured with the Amersham Imager 600 (GE Healthcare). The data were plotted (SigmaPlot, v.11) as a function of protein concentration and fitted to the Hill equation $\left(B=B_{\max }{ }^{*}\left(L^{n} /\left(L^{n}+K_{d}^{n}\right)\right)\right.$ where $B_{\max }$ is a bound fraction of RNA (B) at the saturating protein concentration $L$ and $n$ is the Hill coefficient) to determine dissociation constants $\left(\mathrm{K}_{\mathrm{d}}\right)$.

Table 1. RNA probes for non-isotopic EMSA. ${ }^{1}$ Asterisks denote biotin. ${ }^{2}$ AdML RNA is derived from the adenovirus major late 3 'ss and was previously shown to bind recom binant PUF60 [11]. The last nucleotide of each EMSA probe is at the first exon position.

\begin{tabular}{cc}
\hline Oligoribonucleotide & \multicolumn{1}{c}{ Sequence $\left(5^{\prime}-\mathbf{3}^{\prime}\right)^{\mathbf{1}}$} \\
\hline AdML $^{2}$ & ${ }^{*}$ UUCGUGCUGACCUGUCCCUUUUUUUUCCACAGC \\
\hline UBE2F-can3'ss-32 & ${ }^{*}$ UUUUUUUGUUUUGUUUUGUGUUUUUUGAUAGA \\
\hline UBE2F-cr3'ss-32 & ${ }^{*}$ CUUUUUGUUUCCUUUUUUUUUUUAUUUUAAAGG \\
\hline
\end{tabular}

\subsection{Differential Scanning Fluorimetry (DSF)}

Recombinant proteins were incubated in the 96-well thin-wall PCR plate (Bio-Rad, Hercules, CA, USA) for $10 \mathrm{~min}$ at room temperature. PUF60 reactions contained $9 \mu \mathrm{M}$ of the protein, $70 \mathrm{mM}$ potassium phosphate ( $\mathrm{pH} 7.5$ ), $130 \mathrm{mM} \mathrm{NaCl}, 5 \mathrm{mM} \mathrm{MgCl}_{2}, 1.5 \mathrm{mM} \beta$-mercaptoethanol and $4 \%$ glycerol. U2AF65 reactions contained $8 \mu \mathrm{M}$ of the protein, $50 \mathrm{mM}$ Tris ( $\mathrm{pH} 7.5), 150 \mathrm{mM} \mathrm{NaCl}, 5 \mathrm{mM} \mathrm{MgCl}_{2}, 0.5 \mathrm{mM}$ DTT and $7.5 \%$ glycerol. After incubation, SYPRO Orange dye (Sigma-Aldrich, St. Louis, MO, USA) was added and plates were sealed with Microseal B adhesive sealer (Bio-Rad). After brief centrifugation, samples were heated on the CFX96 Real-Time System (Bio-Rad) from 25 to $95{ }^{\circ} \mathrm{C}$ at a rate of $1{ }^{\circ} \mathrm{C}$ per minute. The reporter was HEX $\left(\lambda_{\mathrm{ex}} 515-535 \mathrm{~nm} / \lambda_{\mathrm{em}} 560-580 \mathrm{~nm}\right)$. The midpoint calculations were determined from the indicated melting curves using the CFX Manager (v. 3.1, Bio-Rad). 


\subsection{Solubility and Stability Predictions}

Solubility profiles with WT and mutant PUF60/U2AF65 were generated by CamSol [27]. The effect of RRM substitutions on protein stability was predicted by the mutation cutoff scanning matrix [28].

\section{Results}

\subsection{Selection of Functional Assays for Cancer-associated Substitutions in PUF60 and U2AF65 RRMs}

To test the response of PUF60-dependent 3'ss [14] to U2AF, we first transiently co-transfected two splicing reporters with constructs expressing the wild-type (WT) U2AF65 into HEK293 cells (Figure 1A). The first reporter was derived from UBE2F exon 5, which requires PUF60 for full inclusion in the mRNA [14]. The second construct contained mutually exclusive OGDH exons $4 \mathrm{a} / 4 \mathrm{~b}$ where PUF60 depletion repressed exon 4b [14]. The U2AF65 overexpression activated a cryptic 3'ss upstream of the canonical 3'ss of UBE2F exon 5 and induced exon skipping (Figure 1B,C). In OGDH, overexpression of either PUF60 or U2AF65 promoted exon 4b, yet individual depletion of the two proteins showed opposite effects of depletion and overexpression on exon $4 \mathrm{a} / 4 \mathrm{~b}$ usage only for PUF60 [14]. A PD-associated mutation in PUF60 RRM (H169Y) [19] failed to activate the cryptic 3'ss of $U B E 2 F$ exon 5 as the WT protein while inducing exon 5 skipping and was unable to promote $O G D H$ exon $4 \mathrm{~b}$. Together, these results indicated that the $U B E 2 F$ reporter should be informative for testing splicing outcomes of cancer-associated RRM mutations in both proteins while OGDH is suitable for examining PUF60 variants.
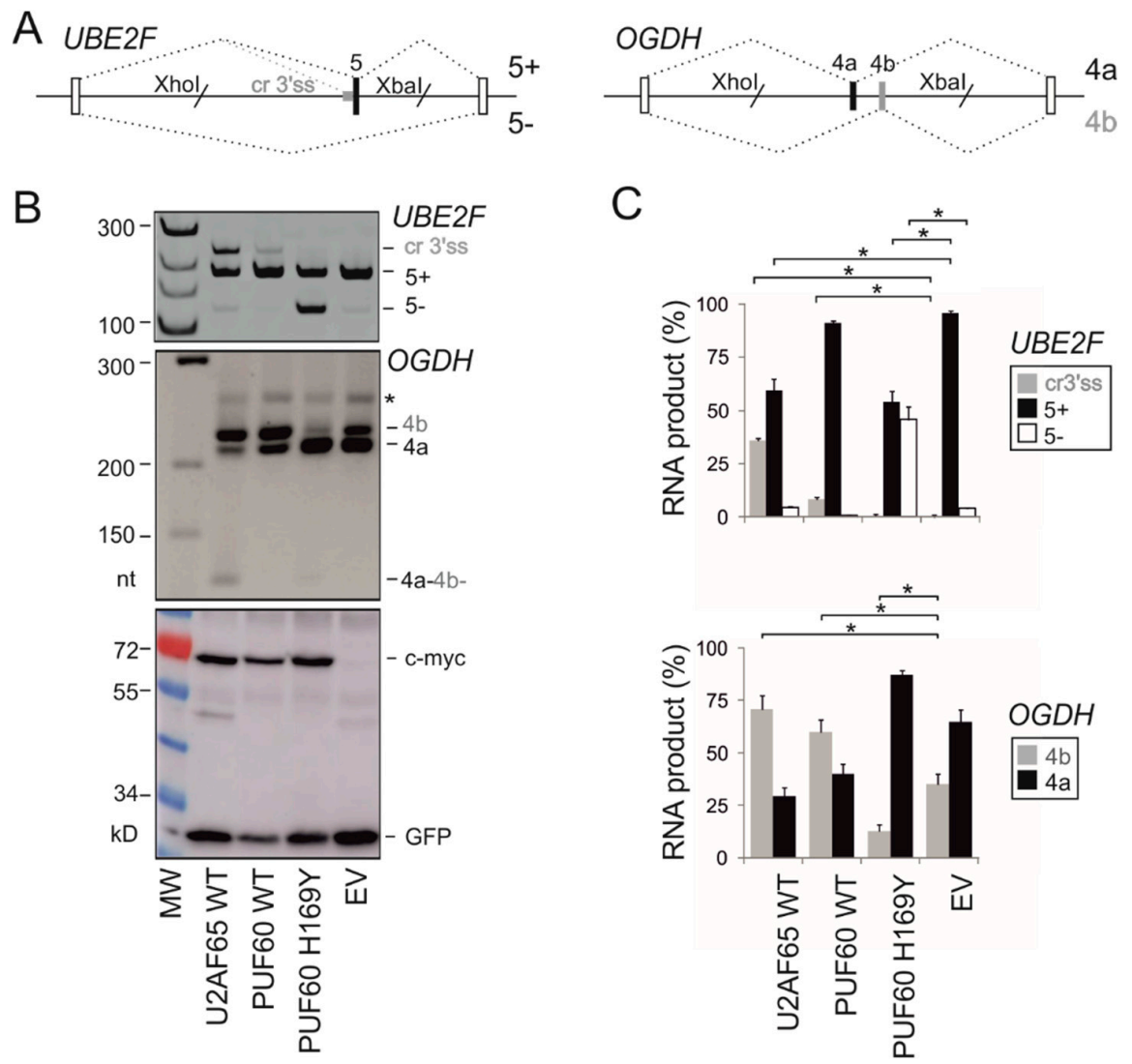

Figure 1. Altered exon usage of PUF60-dependent exons by U2AF65. (A) Schematics of PUF60-dependent hybrid reporter constructs. Their wild-type sequences are in Figure S1. Exons are shown as boxes, introns as horizontal lines, spliced products as dotted diagonal lines above and below the pre-mRNA. Designation of the spliced products is to the right. Grey horizontal rectangle denotes the $(\mathrm{T})_{\mathrm{n}} \mathrm{G}$ repeat of the canonical 3'ss PPT [14], slashes denote restriction sites used for cloning and empty 
boxes represent heterologous exons, as described [25]. (B) UBE2F and OGDH splicing patterns in cells overexpressing the indicated U-binding proteins. MW, molecular weight; EV, empty vector. PUF60 H169Y is a germline substitution reported in the Verheij syndrome [19]. Asterisk denotes slow-mobility heteroduplex DNA formed by annealing of homologous exons $4 \mathrm{a}$ and $4 \mathrm{~b}$. Immunoblotting is shown in the lower panel; antibodies are to the right. (C) Relative abundance of RNA products shown in panel B. Error bars: SDs of two independent transfection experiments. Asterisks denote significant differences ( $p$ values $<0.05$, unpaired two-tailed t-tests) between EV and indicated constructs.

\subsection{PUF60 and U2AF65 RRM Substitutions that Alter 3'ss Usage}

To identify functional RRM substitutions previously reported in cancer cells, we first compiled a list of conserved RRM1 and RRM2 missense mutations (Figure 2, Table S1) from the COSMIC database [9]. COSMIC data showed that missense mutations in cancer patients were reported at relatively high frequencies, both in PUF60 (63\%) and in U2AF65 (71\%). However, it remains uncertain if this may be due to their recurrent occurrences in RRM1 of U2AF65, as suggested by Glasser et al. [15], or in other functional domains (Figure 2). Accumulation of missense mutations in RRMs might be present in other 3'ss recognition factors (Figures S2 and S3A). The clustering of mutations within conserved domains would support their importance in cancer initiation or progression and the role of $U 2 A F 2$ or PUF60 as oncogenes as opposed to tumor suppressors $[29,30]$.

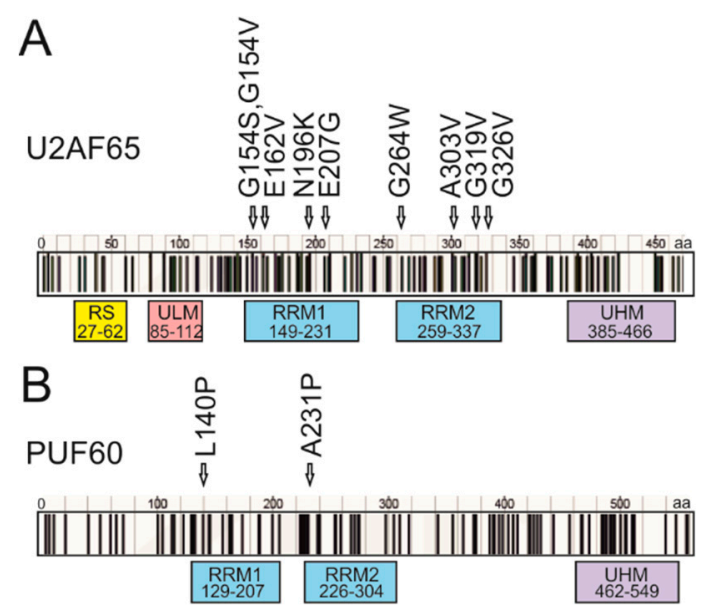

Figure 2. Distribution of cancer-associated substitutions in U2AF65 and PUF60. (A,B) Distribution of somatic missense mutations in the COSMIC database (v. 83). Their frequency is not shown since the COSMIC data could not be corrected for redundant entries, such as repeat samples from the same patient. PUF60 and U2AF65 substitutions that affected pre-mRNA splicing of our tested reporters are shown by arrows above RRM domains. (A) U2AF65. (B) PUF60. RRM alignments with tested substitutions are in Figure S2.

Next, we prepared plasmids expressing U2AF65/PUF60 with mutated RRMs and measured the relative abundance of RNA products that employed competing $3^{\prime}$ ss of UBE2F exon 5 upon transient co-transfections into HEK293 cells (Figures 3 and 4). Of 23 different U2AF65 mutations tested, $10(43 \%)$ altered $3^{\prime}$ ss usage as compared to the WT, despite exhibiting similar overexpression levels on immunoblots. Of 13 tested PUF60 substitutions, 2 (15\%) failed to promote the cryptic 3 'ss and induced exon 5 skipping instead (L140P and A231P, Figure 4A,B). A231P was the only substitution that diminished PUF60 expression (Figure 4A, lower panel). In contrast to PUF60 and U2AF65, expression of the WT SF3B4 in HEK293 cells did not noticeably activate cryptic 3'ss in UBE2F (Figure S3B). 



Figure 3. Splicing activities of cancer-associated U2AF65 RRM substitutions. (A) UBE2F splicing activities (upper panel) and immunoblotting of lysates from transfected HEK293 cells with anti-c-myc antibodies, which detect exogenously expressed protein (lower panel). The relative usage of UBE2F products is quantified at the top. WT, wild-type; EV, empty vector; ${ }^{*}$, double mutant. The bar chart represents the average of four independent transfections \pm SEM. One-way analysis of variance was performed with Dunnett's multiple comparison post-hoc t-tests (STAT200). Asterisks denote significant deviations of mutated plasmids from the WT $(p<0.05)$. Functional substitutions are boxed. dp, degradation product. Dotted horizontal line indicates the level of exon skipping of the WT construct. (B) GANAB splicing activities of U2AF65 RRM substitutions. The reporter is shown in the upper panel; RNA products are to the right. The lower panel shows the relative usage of the spliced products. Error bars are SEMs of two independent transfections. Analysis of variance was performed with Dunnett's multiple comparison post-hoc t-tests (STAT200, Biosoft). Dotted horizontal line denotes exon 6 skipping in the WT. Cryptic $3^{\prime}$ ss at position -53 (Figure S1) was used at $<2 \%$ and was disregarded. 
A

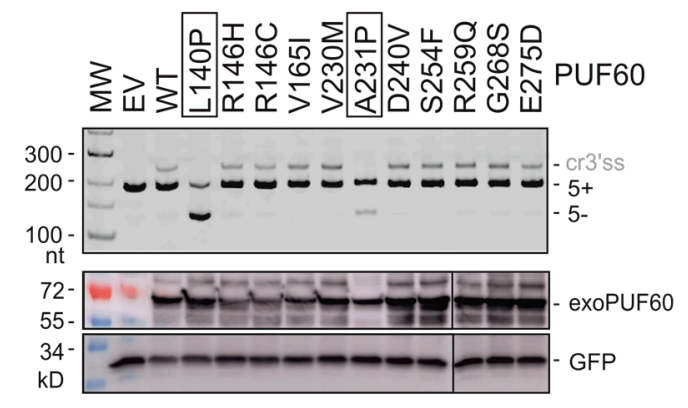

B

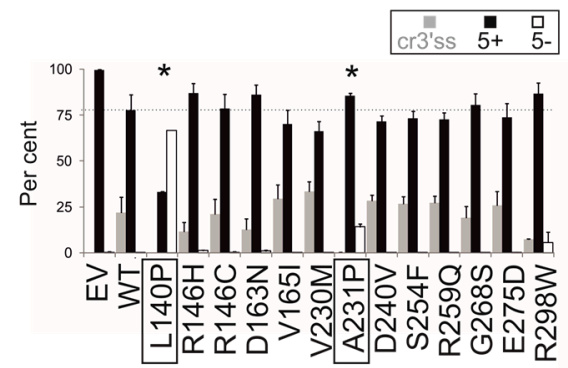

PUF60
C

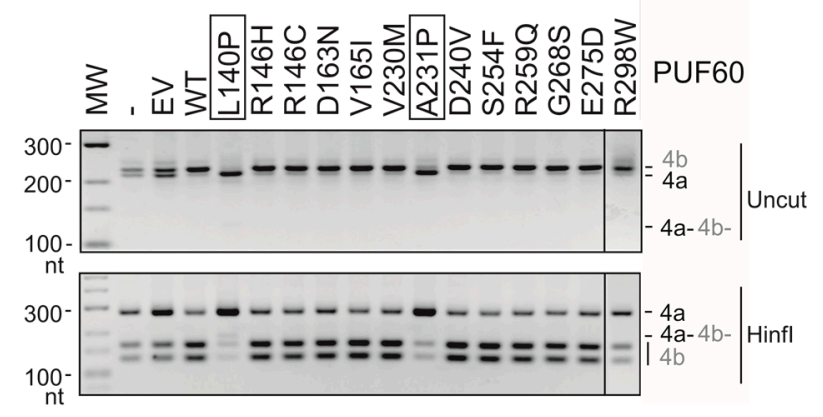

D

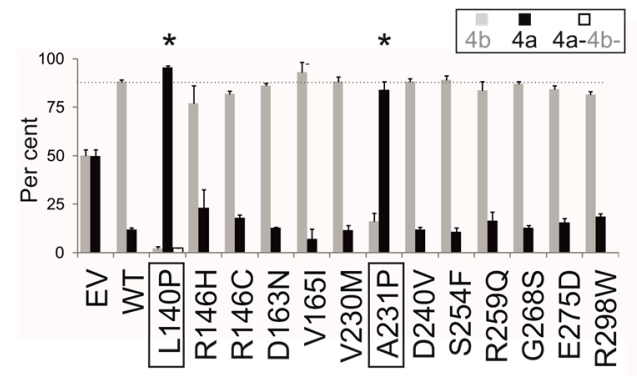

PUF60

Figure 4. Splicing activities of cancer-associated PUF60 RRM substitutions. (A) UBE2F splicing pattern induced by PUF60 expression constructs with the indicated RRM substitutions (upper panel). A corresponding immunoblot is in the lower panel. (B) Relative usage of RNA products shown in panel A. Bar charts represent the means of duplicate transfections \pm SEM. Dotted line indicates canonical transcripts induced by the WT protein. Amino acid substitutions with significant deviations from the WT $(p<0.05)$ are denoted by asterisks at the top and are boxed at the bottom. One-way analysis of variance was performed with Dunnett's multiple comparison post-hoc t-tests. (C) Mutually exclusive usage of $O G D H$ exons in HEK293 cells expressing the indicated constructs. For better resolution, undigested products (upper panel) were also digested with HinfI, which only cleaves exon $4 \mathrm{~b}$ (lower panel). (D) Measurements of mRNA isoforms shown in panel C. Bar charts represent the means of duplicate transfections \pm SEM. Dotted line indicates $4 \mathrm{~b}$ transcripts induced by the WT protein. Amino acid substitutions with significant deviations from the WT $(p<0.05)$ are denoted by asterisks at the top and are boxed at the bottom. Analysis of variance was followed by Dunnett's post-hoc t-tests.

Next, we extended our splicing assays with mutated U2AF65 and PUF60 to GANAB and $O G D H$ reporters, respectively (Figures $3 \mathrm{~B}$ and $4 \mathrm{C}, \mathrm{D})$. GANAB exon 6 is promoted in cells lacking U2AF65 [13,24], possibly via direct binding of U2AF65 to this exon [13]. We found that most U2AF65 substitutions affected splicing of both reporters, including highly conserved G154S/G154V in RRM1 or G264W in RRM2; however, we also observed reporter-specific effects (discussed below). In contrast, both deleterious PUF60 substitutions were concordant.

We also introduced substitution D194Y in the U2AF65 RRM1 since the mutation is located at the same alignment position as the germline substitution PUF60 H169Y (Figure S2), which caused PD [19]. We observed no aberrant splicing with $U B E 2 F$ and GANAB pre-mRNAs (Figure 3). This residue has not sustained any missense changes in cancer cells to date, but a synonymous mutation (c.582C $>\mathrm{T}$; D194D) was found in cancer cells [9].

Because missense, nonsense or synonymous mutations may alter cis-elements required for accurate exon selection [31-33], we examined splicing of a series of reporters containing the same RRM mutations in U2AF2 (Figure 5A-E) or PUF60 (Figure 5F-H) exons. We found that at least one missense (K195R) and one synonymous (D194D) mutation in U2AF2 (Figure 5A-C) and one missense mutation in PUF60 (R298W) significantly increased exon skipping. 
A
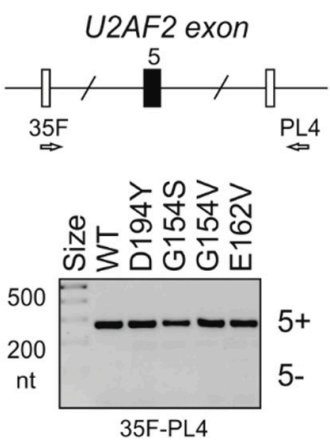

D

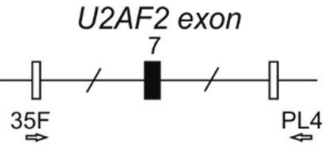

B
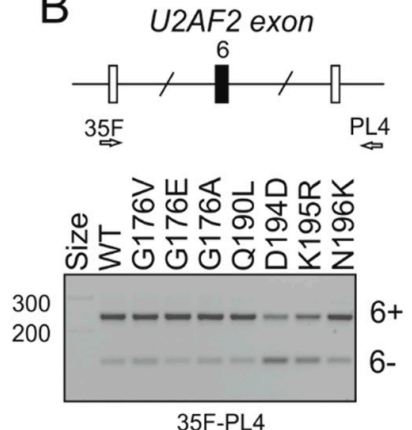

C

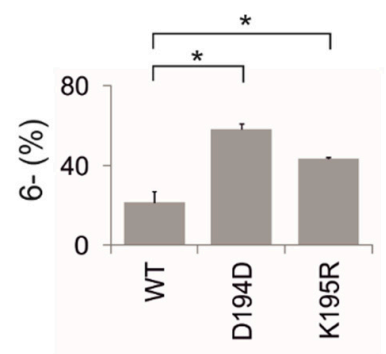

$E$
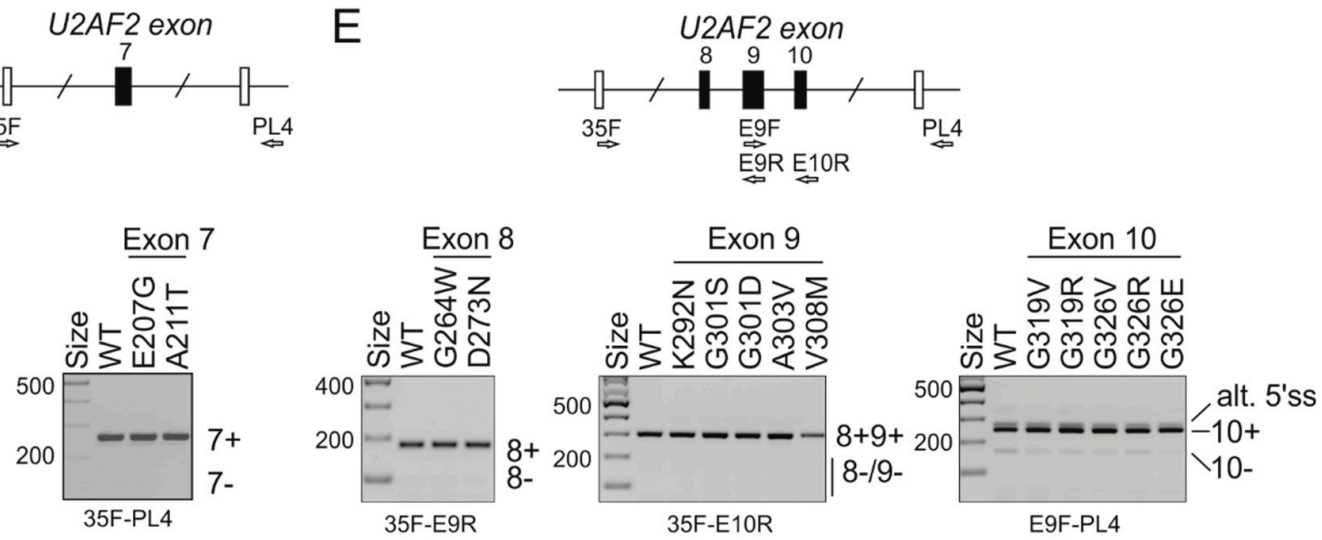

F

G
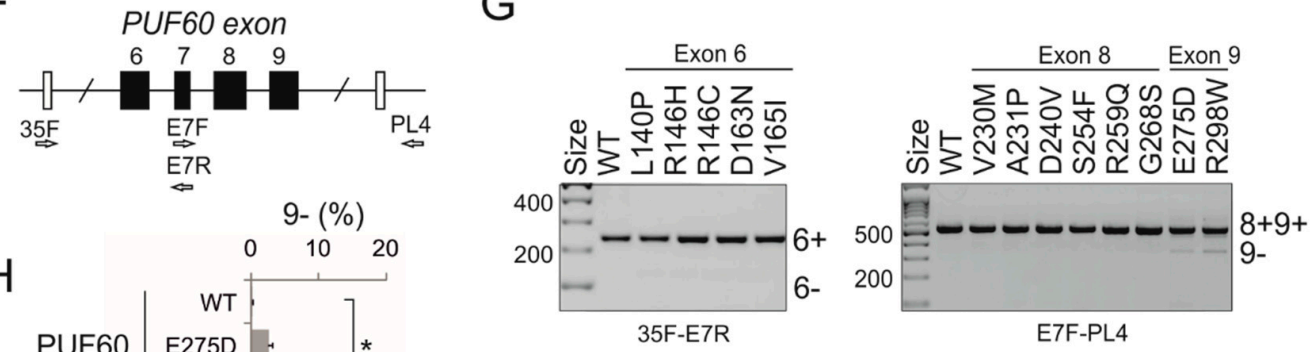

$\mathrm{H}$

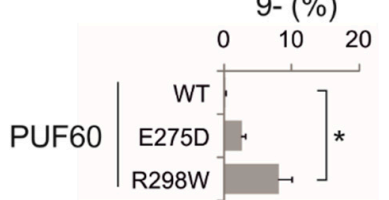

Figure 5. Identification of cancer-associated $U 2 A F 2$ and PUF60 missense mutations that alter exon inclusion in cis. (A-E) U2AF2, (F-H) PUF60. Minigene constructs are schematically depicted above exon-specific panels. Tested exons are denoted by black rectangles and numbered. Terminal minigene exons are shown as open rectangles. RT-PCR primers (Table S2) are denoted by arrows and cloning sites by a slash. RNA products are shown to the right; +, exon inclusion; -, exon exclusion in the mRNA. Exon inclusion levels are in panels C (U2AF2) and H (PUF60). Error bars are SDs (n-method) of two transfection experiments. Asterisks denote significant differences between the WT and mutants $(p<0.05$; one-way analysis variance with Dunnett's multiple comparison post-hoc tests). Alt. 5'ss (panel E) is an alternative GC $5^{\prime}$ ss of $U 2 A F 2$ exon 10, which is used by endogenous HEK293 transcripts at $<25 \%$ [24].

Together, these results show that sensitive 3'ss previously identified by RNA-Seq in cells lacking PUF60 can provide useful substrates for rapid identification of functional cancer-associated RRM mutations not only in PUF60, but also in a cooperating protein. They also demonstrate that distinct RRM substitutions can confer a spectrum of splicing outcomes even for a single intron or exon. Conversely, the same substitutions could impair distinct types of alternative splicing, as illustrated by U2AF65 G154V, which activated cryptic 3'ss in GANAB primary transcripts while inducing UBE2F exon 5 skipping (Figure 3). Finally, our results demonstrate that RRM mutations can have both cis- and trans-acting effects on splicing, further expanding the diversity of mature transcripts (Figures 3-5). 


\subsection{Functional Consequences of Cancer-Associated RRM Substitutions in U2AF65 and PUF60}

To explore mechanisms underlying the observed trans-acting effects (Figures 3 and 4), we employed EMSA and DSF assays with purified recombinant proteins and their putative U-rich targets at sensitive $3^{\prime}$ ss. EMSA with the WT U2AF65 and biotin-labeled oligoribonucleotides derived from the PPT of canonical (can) or cryptic (cr) 3'ss of UBE2F exon 5 (Table 1) revealed similar binding affinities for each probe (Figure 6A,B). As compared to the WT, RNA binding of proteins carrying a subset of functional RRM substitutions was impaired to a varying degree (Figure 6C). DSF profiles (Figure 6D) also revealed variable defects. For G154V, DSF showed two heat absorption peaks, consistent with a biphasic unfolding transition, potentially reflecting a disunited domain unfolding [34], and with the reduced EMSA signals (Figure 6C). This mutation diminished the use of both competing 3'ss, i.e., induced exon 5 skipping (Figure 3A), which was reminiscent of the effect of PUF60 H169Y (Figure 1). In contrast, G319V and E162K showed less severe splicing alterations (Figure 3), a smaller decrease in melting temperatures $\left(\mathrm{T}_{\mathrm{m}}\right)$ in DSF profiles (Figure 6D) and still detectable RNA binding in vitro (Figure 6C, Figure S4). Chemiluminiscent EMSA with E162K showed similar binding affinities to the two UBE2F probes (Figure S4).
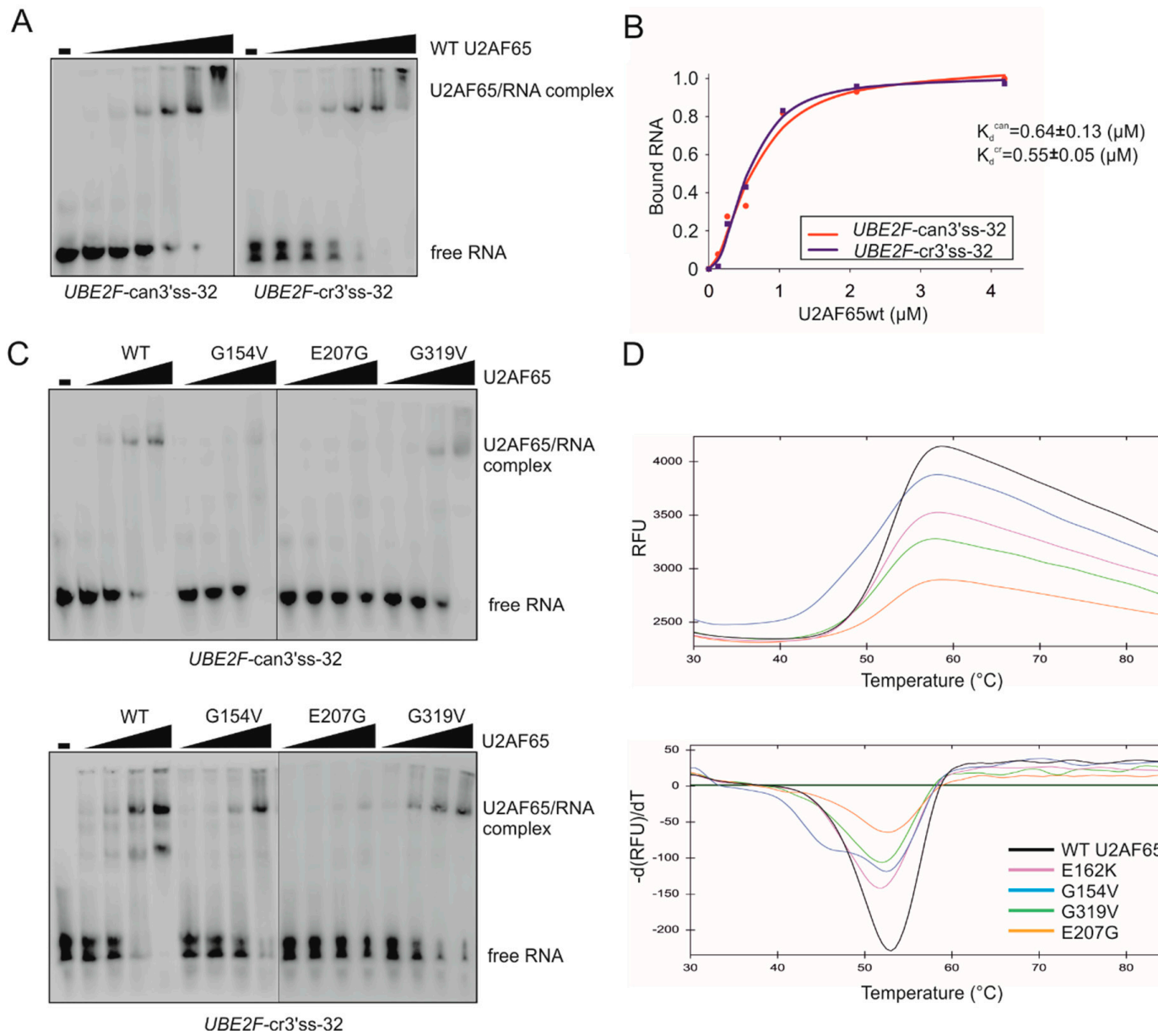

$\mathrm{D}$

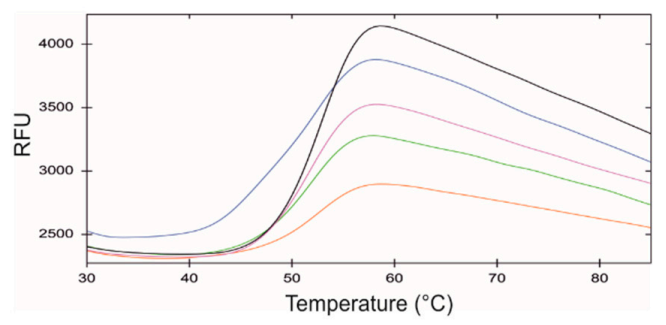

Figure 6. Cancer-associated U2AF65 RRM substitutions impair RNA binding and denaturation profiles. (A) In vitro binding of WT U2AF65 to PPTs of canonical and cryptic 3'ss of UBE2F exon 5, Concentrations of recombinant U2AF65 proteins were $0.13,0.26,0.52,1.05,2.1$ and $4.2 \mu \mathrm{M}$. Sequences of RNA probes are in Table 1. (B) Fractions of bound RNA probes and $\mathrm{K}_{\mathrm{d}}$ estimates. (C) Impaired binding of representative mutated U2AF65 to each PPT. Concentrations of recombinant U2AF65 were 0.26, 0.52, 1.05 and $2.1 \mu \mathrm{M}$. Concentration of biotin-labeled RNAs (bottom) was $17 \mathrm{nM}$. (D) Thermal denaturation profiles of U2AF65 RRM mutants determined by DSF with SYPRO Orange as a thermofluor. Melting curves are in the upper panel and melting peaks are in the lower panel. 
EMSA with WT PUF60 confirmed strong binding to a positive control derived from AdML [11] and showed reduced binding of each cancer-associated RRM mutation that produced trans-acting defects (Figure 7A; Table 1). Their binding to UBE2F oligoribonucleotides was also impaired (Figure S5). H169Y showed an intermediate binding to AdML (Figure 7A). Although binding affinities of the WT PUF60 to PPTs of canonical and cryptic 3'ss of UBE2F exon 5 were similar, H169Y appeared to bind to the former with a higher affinity (Figure 7B,C and Figure S6A,B), which would be consistent with a failure to activate the cryptic 3 'ss (Figure 1). Among tested germline mutations, H169Y also produced the highest amount of RNA products lacking UBE2F exon 5 [14].
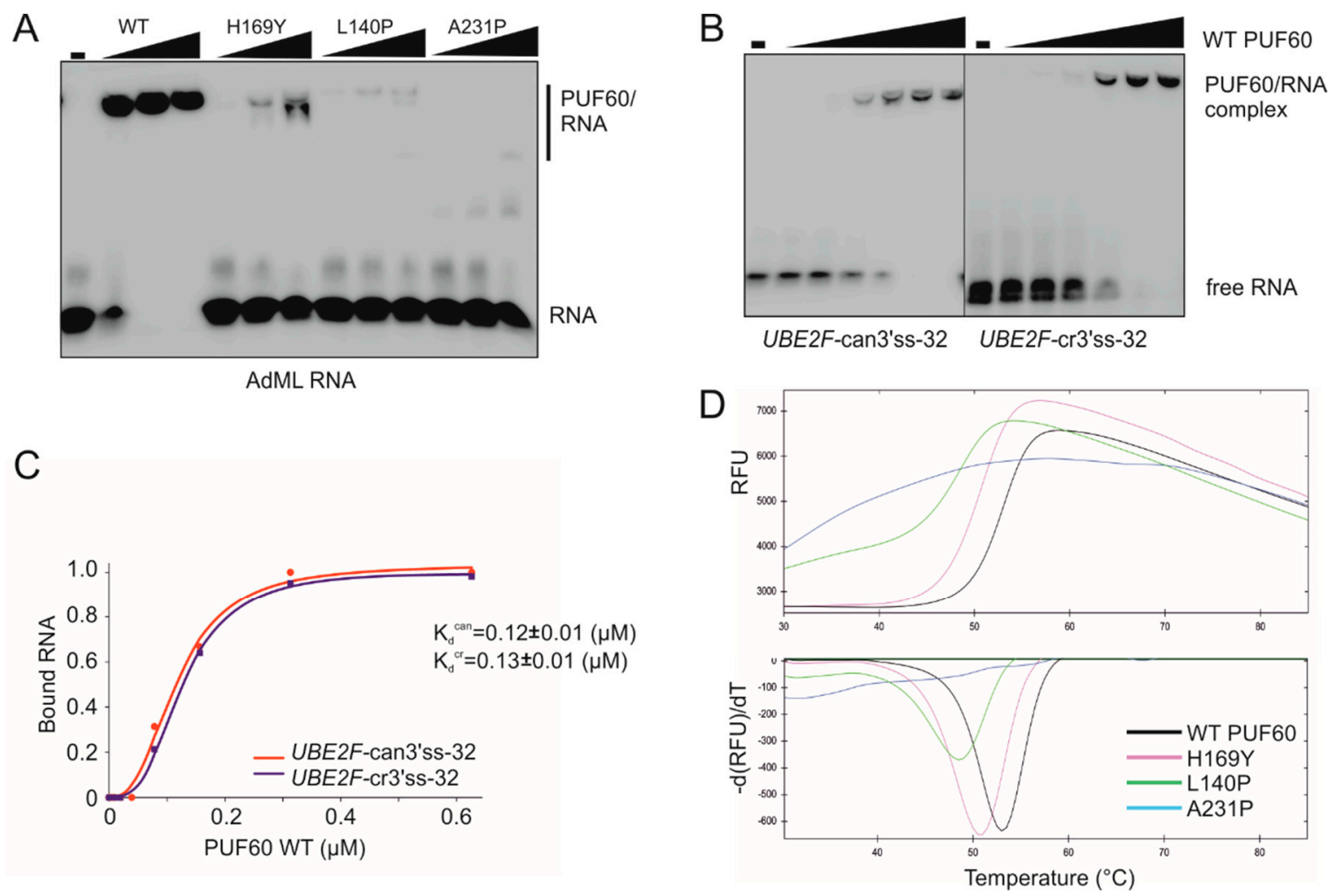

Figure 7. Cancer-associated PUF60 RRM substitutions impair RNA binding and denaturation profiles. (A) Impaired binding of PUF60 with RRM substitutions to the AdML RNA. Concentrations of recombinant proteins were $0.14,0.42$ and $1.25 \mu \mathrm{M}$. The AdML oligoribonucleotide sequence is in Table 1. (B) In vitro binding of WT PUF60 to canonical and cryptic 3'ss of UBE2F exon 5. Concentrations of recombinant PUF60 were 19.5, 39, 78, 156, 312 and 626 nM. RNA probes (bottom) are shown in Table 1. Biotin-labeled RNAs in panels A and B were at $15 \mathrm{nM}$. (C) Graphical representation of bound fractions with mean $K_{d}$ values $( \pm S D$ ). The Hill coefficients were $2.6 \pm 0.3$ (can) and $3.0 \pm 0.2$ (cr). (D) Thermal denaturation profiles of PUF60 RRM mutants determined by DSF.

The hierarchy in AdML EMSA signals for functional PUF60 mutants (WT $>\mathrm{H} 169 \mathrm{Y}>\mathrm{L} 140 \mathrm{P}>\mathrm{A} 231 \mathrm{P}$ ) was mirrored by DSF, with $\mathrm{T}_{\mathrm{m}}$ of H169Y reduced by $\sim 2{ }^{\circ} \mathrm{C}$ and $\mathrm{T}_{\mathrm{m}}$ of L140P by $\sim 4{ }^{\circ} \mathrm{C}$ (Figure 7D). A231P showed flat DSF melting curves indicative of impaired folding, consistent with the diminished signal on immunoblots (Figure 4A). Unlike the WT, each of the three substitutions failed to induce the UBE2F cryptic $3^{\prime}$ ss, but the ratio of UBE2F 5+ and 5- transcripts was consistently higher for A231P than L140P. Both L140P and A231P were resistant to TEV protease cleavage (Figure S7) and were predicted to alter solubility and protein stability by CamSol [27] and the mutation cutoff scanning matrix [28], respectively (Figure S8). Reduced solubility was also predicted for H169Y (Figure S8).

Taken together, U2AF65 or PUF60 RRM substitutions that induce splicing abnormalities in trans not only alter binding affinities to RNAs derived from sensitive 3 'ss but also impair biophysical properties of these proteins, including folding and thermodynamic stability. 


\subsection{Mapping of Cancer-Associated RRM Substitutions on to High-Resolution PUF60 and U2AF65 Structures}

Figure 8 shows examples of functional and neutral RRM substitutions in the context of previously determined structures of U2AF65 (5EV1) [35] and PUF60 (5KW1; Crichlow et al., unpublished) with short U-rich RNAs. In the U2AF65 structure (Figure 8A), the methyl group of A303 in the RNP1 motif makes a van der Waals contact with F304, which interacts with the uracil base of U4. Replacing this methyl group with the bulky side chain of valine produced splicing defects (Figure 3), most likely through altered positioning of F304, which would disrupt the uracil base stacking. Similarly, G264W in the RNP2 motif introduces the aromatic tryptophan side chain, which could interfere with stacking interactions of the uracil base of U3 with the top of the benzene ring of F262. Introducing the bulky tryptophan indole ring is likely to lead to a steric clash with F262 and interfere with U3 binding by RRM2. G154V, which reduced binding to UBE2F 3'ss and eliminated their recognition in cells (Figures 3 and 6C), may have a similar effect on RRM1: Y152 (RNP2) stacks with the uracil base of U7, potentially rearranging the aromatic side chain and disrupting the stacking interaction. G154S, which produced less severe splicing defects (Figure 3), has a smaller side chain as compared to valine, potentially maintaining the U7-Y152 stacking interaction. Thus, these functional substitutions have a strong potential to disrupt interactions with poly(U) RNAs.


Figure 8. Cancer-associated substitutions mapped on to high-resolution RRM structures. (A) Crystal structure of U2AF65 tandem RRMs bound to poly(U) RNA (PDB entry 5EV1) [35]. (B) Crystal structure of PUF60 tandem RRMs bound to a modified AdML 3'ss analogue (PDB entry 5KW1, Crichlow G. V. et al., unpublished). (A,B) Mutated residues (labeled) are shown as space-filling atoms. Substitutions that affected 3 'ss usage are in dark orange; substitutions that had no effect on minigene splicing are in light orange. Proteins (cartoon representation) are shown in purple. RNAs (stick representation) have carbon atoms in green, nitrogen atoms in blue, oxygen atoms in red and phosphorus atoms in orange.

In contrast, a splicing-neutral V308M substitution (Figure 3) maintains a hydrophobic residue in the loop between RNP1 ( $\beta 3$ ) and helix $\alpha 2$ in RRM2 and does not bind to poly(U). Likewise, although G326V/R substitutions change a small glycine to bulky residues in the $\alpha 2-\beta 4$ loop, they are solvent exposed and not in contact with the RNA. On the other hand, E162 is solvent exposed, away from the 
RNA binding site, and E162K did not appear to reduce binding to UBE2F RNAs, yet the substitution showed reproducible DSF and splicing alterations (Figures 3, 6 and 8A).

In the PUF60 structure, functional mutations L140P in RRM1 and A231P in RRM2 (Figures 2,4 and 7) reside in the $\beta 1-\alpha 1$ loop, also far away from the RNA binding surface (Figure $8 \mathrm{~B}$ ). Nevertheless, they may affect RNA binding indirectly by disrupting local hydrophobic interactions, as suggested by DSF (Figure 7D). These substitutions would be predicted to destabilize the fold around the RNP modules. While U2AF65 mutations in the RNPs of RRM2 might directly interfere with poly(U) binding and change 3'ss usage, the substituted prolines in RRMs of PUF60 are likely to have an indirect, structural effect on the RNA binding surface, in turn altering the splicing outcome of PUF60-dependent 3 'ss. By contrast, splicing-neutral V165I in RRM1 ( $\beta 2-\beta 3$ loop) and E275D in RRM2 ( $\beta 3-\alpha 2$ loop) maintain a hydrophobic or acidic amino acid side chain, respectively, and are solvent-exposed without direct RNA contacts (Figure 8B).

Finally, the germline PUF60 H169Y substitution in RRM1 ( $\beta 2-\beta 3$ loop) might also indirectly affect the RNP modules (Figure S9). Interestingly, the distance $(2.9 \AA)$ between the $\mathrm{N}^{\varepsilon 2}$ atom of the imidazole ring and the backbone carbonyl atom of L140 of helix $\alpha 1$ suggests that the $\mathrm{N}^{\varepsilon 2}$ nitrogen is protonated and forms a hydrogen bond with the L140 carbonyl group. This interaction could help stabilize the $\beta 2-\beta 3$ loop and in turn adjacent RNPs. H169Y would eliminate this hydrogen bond and insert a hydrophobic tyrosine ring into the hydrophobic core (I136, M160), altering the local RNP structure, consistent with the splicing defect (Figure 1B,C), lower $\mathrm{T}_{\mathrm{m}}$ detected by DSF (Figure 7D) and lower binding affinities to UBE2F 3'ss (Figure S6). However, although the three functional PUF60 substitutions yielded a wide $T_{m}$ spectrum, the $T_{m}$ values were not completely mirrored by the $5+/ 5$ ratios of UBE2F transcripts (cf. Figures 1, 4 and 7).

\section{Discussion}

We have experimentally characterized the impact of 36 cancer-associated RRM substitutions in PUF60 or U2AF65 on protein properties and splicing in cis and trans. Identification of mutations with trans-acting splicing defects was facilitated by sensitive 3'ss previously found by RNA-seq of cells depleted of PUF60 [14], highlighting the power of this method to identify exploitable targets of important splicing factors in the whole transcriptome. PUF60 and U2AF65 preferentially bind PPTs, interact with each other via their UHM and ULM and cooperate in $3^{\prime}$ ss selection processes [10-12,14]. The transcriptome-wide identification of PUF60-dependent exons revealed that depletion of PUF60 or U2AF65 had often reciprocal effects on 3'ss usage [14] (Figure 1); hence, it is not surprising that functional defects of mutated proteins were detected by a single reporter containing $3^{\prime}$ ss sensitive to both proteins.

PUF60 and U2AF65 are required for accurate recognition of a substantive proportion of 3 'ss $[13,14]$. For U2AF65, this fraction was estimated at $\sim 58 \%$ [36] and 88\% [13], consistent with acting as a major $\mathrm{PPT} / 3^{\prime}$ ss recognizer. The detection rate of functional U2AF65 substitutions also tended to be higher than for PUF60 ( $43 \%$ vs 15\%, $p=0.09$, Fisher's exact test; Figures 3 and 4$)$. Uridines are frequently recognized sequence-specifically by RRM proteins as compared to other ribonucleotides and their recognition is achieved through all nucleotide-binding pockets [16]. This suggests that U2AF65 and PUF60 RRM substitutions may turn out to be important contributors to the mRNA isoform diversity of cancer cells, acting both in cis and trans (Figures 3-5).

The two reporters were concordant for PUF60 variants (Figure 4), but not completely for U2AF65 (Figure 3). This may be attributable to the detection limits of our tests, but also to a higher sensitivity and/or lower variability in the relative abundance of $U B E 2 F$ products, as compared to GANAB. Functional mutations in each protein may also potentially influence other RNA processing or gene expression steps: for example, U2AF is involved in $3^{\prime}$-end processing and PUF60 can also function as a transcriptional repressor [24,37]. Cancer RRM substitutions are likely to create a spectrum of splicing defects of a larger number of 3 'ss than those revealed by our reporters. This spectrum was detected 
even with a single intron, suggesting that a binary classification of RRM substitutions as pathogenic or non-pathogenic is inappropriate.

The majority of RRM substitutions did not show any reduction in overexpression levels (Figures 3 and 4) although we could not exclude minor differences in chemiluminescent signals. Neither PUF60 nor U2AF65 were identified among most dysregulated RBPs in a systematic expression screen across 15 cancer types [38]. Because UHM domain substitutions found in PD diminished PUF60 expression [14], cancer mutations in this domain could affect selection of PUF60-dependent 3'ss globally, potentially mimicking splicing abnormalities previously observed for the PUF60 knockdown [14]. Conversely, overexpression of PUF60 was observed in several cancer types, including hepatic and lung cancer where mRNA levels seem to reflect genomic gains at 8q24.3 around the PUF60 locus and predict poor survival [22,39-41]. The PUF60 overexpression may facilitate detachment of cancer cells on a 3D matrix and their migration was promoted by PUF60 isoforms lacking exon 2/5 [41]. These isoforms produced splicing abnormalities of exogenous transcripts distinct from canonical PUF60 [14].

Our results should also motivate future studies aimed at characterizing the mRNA isoform diversity of PUF60 and U2AF65 RRM substitutions at the level of the whole transcriptome. Impaired alternative splicing of $U B E 2 F, G A N A B$ or $O G D H$ in vivo may be important for cancer initiation or progression. UBE2F is involved in neddylation, which may alter protein function by conjugation of the ubiquitin-like protein NEDD8 to its targets. The process is catalyzed by a neddylation-activating enzyme E1, one of the two neddylation conjugating E2 enzymes (UBE2F and UBE2M), and by E3 ligases, including RBX1/2 [42,43]. UBE2F pairs with RBX2 to regulate cullin 5 whereas UBE2M pairs with RBX1 to mediate neddylation of cullins 1-4 [42]. UBE2F degradation is promoted by UBE2M, which keeps UBE2F in check by activating CRL3, ensuring a cross-talk between E2 and E3 [44]. Overexpression of $U B E 2 F$ mRNA isoforms in cancer predicts poor survival and promotes tumor growth in vitro and in vivo while the UBE2F knockdown is inhibitory [45]. The 33-nt 5' extension of UBE2F exon 5 binds both PUF60 and U2AF65 in vitro (Figures 1, 6 and 7) and is alternatively spliced, introducing extra 11 amino acids (GFFCFVLCFLI) in the peptide. Our RT-PCR assay with a panel of RNAs from human tissues and a forward primer across the cryptic 3'ss visualized a cryptic exon upstream, with the highest relative abundance of the cryptic 3'ss of exon 5 in brain and gonads (Figure S10). However, it remains to be seen whether the differences between tissues reflect tissue-specific expression levels [46], intron 4 variability among RNA donors, kinetics of intron removal or other factors. In the crystal structure model of the NEDD8 E1 ubiquitin-fold domain and the UBE2F core [42], the extra peptide would be inserted in an exposed disordered region between $\beta 2$ and $\beta 3$ sheets, potentially introducing a new interaction surface; however, the impact on neddylation, degradation of pro-apoptotic NOXA [45] or tumor growth remains to be characterized. Finally, splicing abnormalities of UBE2 genes were common in lung carcinomas [47] and UBE2C was found among the most overexpressed transcripts [48].

UBE2F exon 5 is one of the most sensitive PUF60 targets in the whole transcriptome [14]. The 3'ss of exon 5 has an unusual upstream competitor separated by $(U)_{n} G$ repeats that bind both PUF60 and U2AF65 in vitro (Figures 6 and 7, Figures S5 and S6). The two 3'ss employ distinct lariat branch sites; the downstream branch site is embedded in the cryptic $3^{\prime}$ ss consensus [14]. Apart from repressing both 3'ss and exon skipping (G154V or N196K), RRM substitutions seemed to impair the fine balance between 3'ss in either direction ( $c f$. G154S or E207G with E162K or G319V) (Figure 3). How exactly this putative bidirectional effect on selection of 3'ss competitors reflects impaired U2AF65 interactions with protein partners and specific RNA targets remains to be seen. This phenomenon evokes the co-existence of loss- and gain-of-function mutations in the same protein domains in cancer cells, as exemplified by activating and inactivating missense mutations in DNA-binding or kinase domains [29,30,49,50].

GANAB exon 6 encodes 22 amino acids that interrupt a unique disordered B1 subdomain of glucosidase II $\alpha[51,52]$. The first post-translationally modified residue in the peptide has been recently identified (DKIKNLF, the underlined lysine is ubiquitinylated) [53], but the precise role of the two isoforms is obscure. GANAB was among proteins most enriched in acidic exosomes implicated in melanoma progression, with high expression levels associated with poor prognosis [54]. It interacts 
with the short secreted isoform of ADAM12, which is overexpressed in many tumor types [55]. Knockdown of GANAB or PRKCSH, which encode the glucosidase II heterodimer, reduced Wnt3 secretion by $40 \%-50 \%$, arguing for the role in Wnt signalling [56]. Finally, knockdown of OGDH was associated with profound growth defects in a subset of cancer cell lines, potentially providing a therapeutic target in a metabolically distinct subset of tumors [57], although the distinct function of mRNA isoforms was not addressed.

Cancer mutations found in U2AF2 were previously mapped to U2AF65 structures [15]. For example, N196K changes the RRM1 conformation to bind a uracil base [15] and leads to exon skipping (Figure 3). In contrast, U2AF65 G176 substitutions did not change the conformation to bind RNA [15] and induced no detectable splicing alterations (Figure 3). U2AF65 G301I reduced binding affinity to d(U) 20 , but the reduction was the smallest among tested mutations; G301I also packs against the sugar-phosphate backbone of uridine rather than interacting with the base [58]. In our assays, G301S did not show a splicing defect (Figure 3), but we cannot exclude that it would affect the use of other 3'ss. On the other hand, binding affinities of some mutants do not fully explain the splicing pattern. U2AF65 E207G showed a reduced EMSA signal with each UBE2F RNA probe (Figure 6C), but canonical $3^{\prime}$ ss was still selected albeit less efficiently than for EV controls (Figure 3). In addition, binding of E162K to each probe (Figure S4) was similar, although the discrimination power of chemiluminescent EMSA may not disclose minor $\mathrm{K}_{\mathrm{d}}$ changes. It is also worth mentioning that some cancer-associated PUF60 substitutions, such as V230M [59] or A231P [60], are at the same alignment positions that were previously implicated in side chain contacts between U2AF65 and U7 RNA (Figure S2) [58].

Finally, SF3B4 is a component of the SF3b complex required for branch site recognition [61], is the only SF3b protein with two RRMs adjacent to each other [62] and also has RNA binding preferences for GU-rich motifs, largely through RRM2 [63], yet our PPT reporters failed to respond (Figure S3). Whether this reflects a distinct set of SF3B4-dependent target 3'ss, rather than a lower expression of SF3B4 in our system, remains to be seen. In this respect, KLF4 exon 3 has been recently proposed to be a prominent SF3B4 target, potentially acting in early-stage hepatocellular carcinomas [64]. Loss-of-function SF3B4 mutations in the germline lead to acrofacial dysostosis syndromes, including Nager/Rodriguez syndromes, and RNA-seq of mutated chondrocytes detected many splicing alterations [65], which may yield suitable reporter $3^{\prime}$ ss for future testing of cancer variants.

\section{Conclusions}

Here we have exploited publicly available RNA-seq data to develop screening assays of cancer-associated PUF60/U2AF65 RRM substitutions to identify functional mutations. We found that besides RNA binding and 3'ss selection defects, a subset of RRM substitutions altered protein folding and stability and generated an unexpected mRNA diversity by promoting or repressing 3'ss competitors in their pre-mRNA targets. This diversity may be further enhanced by variable skipping of PUF60 or U2AF2 internal exons observed for a small fraction of RRM missense mutations. These results will facilitate functional characterization of RRM mutations in cancer cells in the future.

Supplementary Materials: The following Tables and Figures are available online at http://www.mdpi.com/20726694/12/7/1865/s1; Table S1. Characterization of tested mutations; Table S2. Cloning and RT-PCR primers; Figure S1. Sequences of wild-type splicing reporter inserts; Figure S2. Alignment of human U2AF65, PUF60 and SF3B4 RRMs; Figure S3. Splicing pattern of PUF60-/U2AF65-dependent reporters in cells overexpressing SF3B4; Figure S4. U2AF65 E162K binding to oligoribonucleotides derived from canonical and cryptic 3'ss of UBE2F exon 5; Figure S5. Non-isotopic EMSA with WT and mutated PUF60 and RNA probes derived from competing 3'sS of UBE2F exon 5; Figure S6. Binding of PUF60 H169Y to UBE2F-derived oligoribonucleotides; Figure S7. PUF60 L140P and A231P induce protein destabilization and misfolding; Figure S8. Solubility and stability profiles of wild type and mutated PUF60 or U2AF65; Figure S9. H169Y in the crystal structure of PUF60 RRM1; Figure S10. Utilization of cryptic $3^{\prime}$ ss of $U B E 2 F$ exon 5 in human tissues.

Author Contributions: Conceptualization, I.V., and J.K.; methodology, I.B., J.K., M.K., P.J.L., and I.V.; validation, J.K., P.J.L., and I.V.; analysis, I.B., J.K., M.K., P.J.L., and I.V.; resources J.K., P.J.L., and I.V.; writing-original draft preparation, J.K., I.B., P.J.L., and I.V.; writing一review and editing, J.K., I.B., P.J.L., and I.V.; writing一review 
and editing, J.K., I.B., P.J.L., and I.V.; visualization, J.K., and I.V., supervision, J.K., I.B., P.J.L., and I.V.; project administration, I.V.; funding acquisition, J.K., P.J.L. and I.V. All authors have read and agreed to the manuscript.

Funding: This study was supported by grants from Bloodwise to I.V. [award 12060], VEGA [award 2/0057/18] and the Slovak Research and Development Agency [APVV-18-0096] to J.K., the Marie Curie Career Integration Grant (PCIG14-GA-2013-630758) to P.J.L. and by patent royalties to J.K. and I.V. as declared below. The article open access fee was funded by the COAF UK.

Acknowledgments: We wish to thank Andrew Berglund (University at Albany), Michelle Hastings (Chicago University Medical School) and Adrian Krainer (Cold Spring Harbor Laboratory) for generous gifts of reagents.

Conflicts of Interest: The authors declare no conflict of interest.

\section{Abbreviations}

AdML: adenovirus major late; COSMIC: catalog of somatic mutations in cancer; DSF: differential scanning fluorimetry; DTT: dithiothreitol; EDTA: ethylenediaminetetraacetic acid; EMSA: electrophoretic mobility shift assay; GFP: green fluorescent protein; GST: glutathione $S$ transferase; HEK: human embryonal kidney; HEPES: 4-(2-hydroxyethyl)-1-piperazineethanesulfonic acid; HEX: hexachlorofluorescein; IMAC: immobilized metal affinity chromatography; IPTG: isopropyl $\beta$-D-1-thiogalactopyranoside; MMLV: Moloney murine leukemia virus; PUF60: poly(U)-binding splicing factor $60 \mathrm{kDa}$; RRM: RNA recognition motif; RT-PCR: reverse transcriptase polymerase chain reaction; SDS-PAGE: sodium dodecyl sulfate polyacrylamide gel electrophoresis; TEV: tobacco etch virus; U: uridine; U2AF65: 65-kD subunit of the auxiliary factor of U2 small nuclear ribonucleoprotein; UHM: U2AF-homology motif; ULM: UHM-ligand motif; WT: wild-type.

\section{References}

1. Yoshida, K.; Sanada, M.; Shiraishi, Y.; Nowak, D.; Nagata, Y.; Yamamoto, R.; Sato, Y.; Sato-Otsubo, A.; Kon, A.; Nagasaki, M.; et al. Frequent pathway mutations of splicing machinery in myelodysplasia. Nature 2011, 478, 64-69. [CrossRef]

2. Okeyo-Owuor, T.; White, B.S.; Chatrikhi, R.; Mohan, D.R.; Kim, S.; Griffith, M.; Ding, L.; Ketkar-Kulkarni, S.; Hundal, J.; Laird, K.M.; et al. U2AF1 mutations alter sequence specificity of pre-mRNA binding and splicing. Leukemia 2015, 29, 909-917. [CrossRef] [PubMed]

3. Inoue, D.; Bradley, R.K.; Abdel-Wahab, O. Spliceosomal gene mutations in myelodysplasia: Molecular links to clonal abnormalities of hematopoiesis. Genes Dev. 2016, 30, 989-1001. [CrossRef]

4. Yoshida, H.; Park, S.Y.; Oda, T.; Akiyoshi, T.; Sato, M.; Shirouzu, M.; Tsuda, K.; Kuwasako, K.; Unzai, S.; Muto, Y.; et al. A novel 3' splice site recognition by the two zinc fingers in the U2AF small subunit. Genes Dev. 2015, 29, 1649-1660. [CrossRef]

5. Cretu, C.; Schmitzova, J.; Ponce-Salvatierra, A.; Dybkov, O.; De Laurentiis, E.I.; Sharma, K.; Will, C.L.; Urlaub, H.; Luhrmann, R.; Pena, V. Molecular Architecture of SF3b and Structural Consequences of Its Cancer-Related Mutations. Mol. Cell 2016, 64, 307-319. [CrossRef] [PubMed]

6. Alsafadi, S.; Houy, A.; Battistella, A.; Popova, T.; Wassef, M.; Henry, E.; Tirode, F.; Constantinou, A.; Piperno-Neumann, S.; Roman-Roman, S.; et al. Cancer-associated SF3B1 mutations affect alternative splicing by promoting alternative branchpoint usage. Nat. Commun. 2016, 7, 10615. [CrossRef] [PubMed]

7. Carrocci, T.J.; Zoerner, D.M.; Paulson, J.C.; Hoskins, A.A. SF3b1 mutations associated with myelodysplastic syndromes alter the fidelity of branchsite selection in yeast. Nucleic Acids Res. 2017, 45, 4837-4852. [CrossRef] [PubMed]

8. Darman, R.B.; Seiler, M.; Agrawal, A.A.; Lim, K.H.; Peng, S.; Aird, D.; Bailey, S.L.; Bhavsar, E.B.; Chan, B.; Colla, S.; et al. Cancer-Associated SF3B1 Hotspot Mutations Induce Cryptic 3' Splice Site Selection through Use of a Different Branch Point. Cell Rep. 2015, 13, 1033-1045. [CrossRef] [PubMed]

9. Forbes, S.A.; Beare, D.; Boutselakis, H.; Bamford, S.; Bindal, N.; Tate, J.; Cole, C.G.; Ward, S.; Dawson, E.; Ponting, L.; et al. COSMIC: Somatic cancer genetics at high-resolution. Nucleic Acids Res. 2017, 45, D777-D783. [CrossRef]

10. Page-McCaw, P.S.; Amonlirdviman, K.; Sharp, P.A. PUF60: A novel U2AF65-related splicing activity. RNA 1999, 5, 1548-1560. [CrossRef]

11. Hastings, M.L.; Allemand, E.; Duelli, D.M.; Myers, M.P.; Krainer, A.R. Control of pre-mRNA splicing by the general splicing factors PUF60 and U2AF. PLoS ONE 2007, 2, e538. [CrossRef] [PubMed] 
12. Corsini, L.; Hothorn, M.; Stier, G.; Rybin, V.; Scheffzek, K.; Gibson, T.J.; Sattler, M. Dimerization and protein binding specificity of the U2AF homology motif of the splicing factor PUF60. J. Biol. Chem. 2009, 284, 630-639. [CrossRef] [PubMed]

13. Shao, C.; Yang, B.; Wu, T.; Huang, J.; Tang, P.; Zhou, Y.; Zhou, J.; Qiu, J.; Jiang, L.; Li, H.; et al. Mechanisms for U2AF to define $3^{\prime}$ splice sites and regulate alternative splicing in the human genome. Nat. Struct. Mol. Biol. 2014, 21, 997-1005. [CrossRef] [PubMed]

14. Kralovicova, J.; Sevcikova, I.; Stejskalova, E.; Obuca, M.; Hiller, M.; Stanek, D.; Vorechovsky, I. PUF60-activated exons uncover altered $3^{\prime}$ splice-site selection by germline missense mutations in a single RRM. Nucleic Acids Res. 2018, 46, 6166-6187. [CrossRef]

15. Glasser, E.; Agrawal, A.A.; Jenkins, J.L.; Kielkopf, C.L. Cancer-Associated Mutations Mapped on High-Resolution Structures of the U2AF2 RNA Recognition Motifs. Biochemistry 2017, 56, 4757-4761. [CrossRef]

16. Afroz, T.; Cienikova, Z.; Clery, A.; Allain, F.H. One, Two, Three, Four! How Multiple RRMs Read the Genome Sequence. Methods Enzymol. 2015, 558, 235-278. [CrossRef]

17. Zamore, P.D.; Green, M.R. Identification, purification, and biochemical characterization of U2 small nuclear ribonucleoprotein auxiliary factor. Proc. Natl. Acad. Sci. USA 1989, 86, 9243-9247. [CrossRef]

18. Zamore, P.D.; Patton, J.G.; Green, M.R. Cloning and domain structure of the mammalian splicing factor U2AF. Nature 1992, 355, 609-614. [CrossRef]

19. Dauber, A.; Golzio, C.; Guenot, C.; Jodelka, F.M.; Kibaek, M.; Kjaergaard, S.; Leheup, B.; Martinet, D.; Nowaczyk, M.J.; Rosenfeld, J.A.; et al. SCRIB and PUF60 are primary drivers of the multisystemic phenotypes of the 8q24.3 copy-number variant. Am. J. Hum. Genet. 2013, 93, 798-811. [CrossRef]

20. El Chehadeh, S.; Kerstjens-Frederikse, W.S.; Thevenon, J.; Kuentz, P.; Bruel, A.L.; Thauvin-Robinet, C.; Bensignor, C.; Dollfus, H.; Laugel, V.; Riviere, J.B.; et al. Dominant variants in the splicing factor PUF60 cause a recognizable syndrome with intellectual disability, heart defects and short stature. Eur. J. Hum. Genet. 2016, 25, 43-51. [CrossRef]

21. Matsushita, K.; Tomonaga, T.; Shimada, H.; Shioya, A.; Higashi, M.; Matsubara, H.; Harigaya, K.; Nomura, F.; Libutti, D.; Levens, D.; et al. An essential role of alternative splicing of c-myc suppressor FUSE-binding protein-interacting repressor in carcinogenesis. Cancer Res. 2006, 66, 1409-1417. [CrossRef] [PubMed]

22. Malz, M.; Bovet, M.; Samarin, J.; Rabenhorst, U.; Sticht, C.; Bissinger, M.; Roessler, S.; Bermejo, J.L.; Renner, M.; Calvisi, D.F.; et al. Overexpression of far upstream element (FUSE) binding protein (FBP)-interacting repressor (FIR) supports growth of hepatocellular carcinoma. Hepatology 2014, 60, 1241-1250. [CrossRef] [PubMed]

23. Kralovicova, J.; Vorechovsky, I. Allele-dependent recognition of the 3' splice site of INS intron 1. Hum. Genet. 2010, 128, 383-400. [CrossRef] [PubMed]

24. Kralovicova, J.; Knut, M.; Cross, N.C.; Vorechovsky, I. Identification of U2AF(35)-dependent exons by RNA-Seq reveals a link between $3^{\prime}$ splice-site organization and activity of U2AF-related proteins. Nucleic Acids Res. 2015, 43, 3747-3763. [CrossRef] [PubMed]

25. Kralovicova, J.; Vorechovsky, I. Alternative splicing of U2AF1 reveals a shared repression mechanism for duplicated exons. Nucleic Acids Res. 2017, 45, 417-434. [CrossRef] [PubMed]

26. Kralovicova, J.; Houngninou-Molango, S.; Kramer, A.; Vorechovsky, I. Branch site haplotypes that control alternative splicing. Hum. Mol. Genet. 2004, 13, 3189-3202. [CrossRef]

27. Sormanni, P.; Aprile, F.A.; Vendruscolo, M. The CamSol method of rational design of protein mutants with enhanced solubility. J. Mol. Biol. 2015, 427, 478-490. [CrossRef]

28. Pires, D.E.; Ascher, D.B.; Blundell, T.L. mCSM: Predicting the effects of mutations in proteins using graph-based signatures. Bioinformatics 2014, 30, 335-342. [CrossRef]

29. Vorechovsky, I.; Luo, L.; Dyer, M.J.; Catovsky, D.; Amlot, P.L.; Yaxley, J.C.; Foroni, L.; Hammarstrom, L.; Webster, A.D.; Yuille, M.A. Clustering of missense mutations in the ataxia-telangiectasia gene in a sporadic T-cell leukaemia. Nat. Genet. 1997, 17, 96-99. [CrossRef]

30. Yang, F.; Petsalaki, E.; Rolland, T.; Hill, D.E.; Vidal, M.; Roth, F.P. Protein domain-level landscape of cancer-type specific somatic mutations. PLoS Comput. Biol. 2015, 11, e1004147. [CrossRef]

31. Cartegni, L.; Chew, S.L.; Krainer, A.R. Listening to silence and understanding nonsense: Exonic mutations that affect splicing. Nat. Rev. Genet. 2002, 3, 285-298. [CrossRef] [PubMed]

32. Pagani, F.; Baralle, F.E. Genomic variants in exons and introns: Identifying the splicing spoilers. Nat. Rev. Genet. 2004, 5, 389-396. [CrossRef] [PubMed] 
33. Raponi, M.; Kralovicova, J.; Copson, E.; Divina, P.; Eccles, D.; Johnson, P.M.; Baralle, D.; Vorechovsky, I. Prediction of single-nucleotide substitutions that result in exon skipping: Identification of a splicing silencer in BRCA1 exon 5. Hum. Mutat. 2011, 32, 436-444. [CrossRef] [PubMed]

34. Niesen, F.H.; Berglund, H.; Vedadi, M. The use of differential scanning fluorimetry to detect ligand interactions that promote protein stability. Nat. Protoc. 2007, 2, 2212-2221. [CrossRef] [PubMed]

35. Agrawal, A.A.; Salsi, E.; Chatrikhi, R.; Henderson, S.; Jenkins, J.L.; Green, M.R.; Ermolenko, D.N.; Kielkopf, C.L. An extended U2AF(65)-RNA-binding domain recognizes the $3^{\prime}$ splice site signal. Nat. Commun. 2016, 7, 10950. [CrossRef]

36. Zarnack, K.; Konig, J.; Tajnik, M.; Martincorena, I.; Eustermann, S.; Stevant, I.; Reyes, A.; Anders, S.; Luscombe, N.M.; Ule, J. Direct competition between hnRNP C and U2AF65 protects the transcriptome from the exonization of Alu elements. Cell 2013, 152, 453-466. [CrossRef]

37. Cukier, C.D.; Hollingworth, D.; Martin, S.R.; Kelly, G.; Diaz-Moreno, I.; Ramos, A. Molecular basis of FIR-mediated c-myc transcriptional control. Nat. Struct. Mol. Biol. 2010, 17, 1058-1064. [CrossRef]

38. Wang, Z.L.; Li, B.; Luo, Y.X.; Lin, Q.; Liu, S.R.; Zhang, X.Q.; Zhou, H.; Yang, J.H.; Qu, L.H. Comprehensive Genomic Characterization of RNA-Binding Proteins across Human Cancers. Cell Rep. 2018, 22, 286-298. [CrossRef]

39. Cheng, L.; Wang, P.; Yang, S.; Yang, Y.; Zhang, Q.; Zhang, W.; Xiao, H.; Gao, H.; Zhang, Q. Identification of genes with a correlation between copy number and expression in gastric cancer. BMC Med. Genomics 2012, 5, 14. [CrossRef]

40. Ramakrishna, M.; Williams, L.H.; Boyle, S.E.; Bearfoot, J.L.; Sridhar, A.; Speed, T.P.; Gorringe, K.L.; Campbell, I.G. Identification of candidate growth promoting genes in ovarian cancer through integrated copy number and expression analysis. PLoS ONE 2010, 5, e9983. [CrossRef]

41. Muller, B.; Bovet, M.; Yin, Y.; Stichel, D.; Malz, M.; Gonzalez-Vallinas, M.; Middleton, A.; Ehemann, V.; Schmitt, J.; Muley, T.; et al. Concomitant expression of far upstream element (FUSE) binding protein (FBP) interacting repressor (FIR) and its splice variants induce migration and invasion of non-small cell lung cancer (NSCLC) cells. J. Pathol. 2015, 237, 390-401. [CrossRef] [PubMed]

42. Huang, D.T.; Ayrault, O.; Hunt, H.W.; Taherbhoy, A.M.; Duda, D.M.; Scott, D.C.; Borg, L.A.; Neale, G.; Murray, P.J.; Roussel, M.F.; et al. E2-RING expansion of the NEDD8 cascade confers specificity to cullin modification. Mol. Cell 2009, 33, 483-495. [CrossRef] [PubMed]

43. Zhao, Y.; Morgan, M.A.; Sun, Y. Targeting Neddylation pathways to inactivate cullin-RING ligases for anticancer therapy. Antioxid. Redox. Signal 2014, 21, 2383-2400. [CrossRef]

44. Zhou, W.; Xu, J.; Tan, M.; Li, H.; Li, H.; Wei, W.; Sun, Y. UBE2M is a Stress-Inducible Dual E2 for Neddylation and Ubiquitylation that Promotes Targeted Degradation of UBE2F. Mol. Cell 2018, 70, 1008-1024. [CrossRef]

45. Zhou, W.; Xu, J.; Li, H.; Xu, M.; Chen, Z.J.; Wei, W.; Pan, Z.; Sun, Y. Neddylation E2 UBE2F Promotes the Survival of Lung Cancer Cells by Activating CRL5 to Degrade NOXA via the K11 Linkage. Clin. Cancer Res. 2017, 23, 1104-1116. [CrossRef]

46. Dowhan, D.H.; Hong, E.P.; Auboeuf, D.; Dennis, A.P.; Wilson, M.M.; Berget, S.M.; O'Malley, B.W. Steroid hormone receptor coactivation and alternative RNA splicing by U2AF65-related proteins CAPERalpha and CAPERbeta. Mol. Cell 2005, 17, 429-439. [CrossRef]

47. Li, Y.; Sun, N.; Lu, Z.; Sun, S.; Huang, J.; Chen, Z.; He, J. Prognostic alternative mRNA splicing signature in non-small cell lung cancer. Cancer Lett. 2017, 393, 40-51. [CrossRef]

48. Han, S.S.; Kim, W.J.; Hong, Y.; Hong, S.H.; Lee, S.J.; Ryu, D.R.; Lee, W.; Cho, Y.H.; Lee, S.; Ryu, Y.J.; et al. RNA sequencing identifies novel markers of non-small cell lung cancer. Lung Cancer 2014, 84, 229-235. [CrossRef]

49. Baugh, E.H.; Ke, H.; Levine, A.J.; Bonneau, R.A.; Chan, C.S. Why are there hotspot mutations in the TP53 gene in human cancers? Cell Death Differ. 2018, 25, 154-160. [CrossRef]

50. Dixit, A.; Verkhivker, G.M. Structure-functional prediction and analysis of cancer mutation effects in protein kinases. Comp. Math. Methods Med. 2014, 2014, 653487. [CrossRef]

51. Arendt, C.W.; Dawicki, W.; Ostergaard, H.L. Alternative splicing of transcripts encoding the alpha- and beta-subunits of mouse glucosidase II in T lymphocytes. Glycobiology 1999, 9, 277-283. [CrossRef] [PubMed]

52. Satoh, T.; Toshimori, T.; Yan, G.; Yamaguchi, T.; Kato, K. Structural basis for two-step glucose trimming by glucosidase II involved in ER glycoprotein quality control. Sci. Rep. 2016, 6, 20575. [CrossRef] [PubMed] 
53. Akimov, V.; Barrio-Hernandez, I.; Hansen, S.V.F.; Hallenborg, P.; Pedersen, A.K.; Bekker-Jensen, D.B.; Puglia, M.; Christensen, S.D.K.; Vanselow, J.T.; Nielsen, M.M.; et al. UbiSite approach for comprehensive mapping of lysine and N-terminal ubiquitination sites. Nat. Struct. Mol. Biol. 2018, 25, 631-640. [CrossRef] [PubMed]

54. Boussadia, Z.; Lamberti, J.; Mattei, F.; Pizzi, E.; Puglisi, R.; Zanetti, C.; Pasquini, L.; Fratini, F.; Fantozzi, L.; Felicetti, F.; et al. Acidic microenvironment plays a key role in human melanoma progression through a sustained exosome mediated transfer of clinically relevant metastatic molecules. J. Exp. Clin. Cancer Res. 2018, 37, 245. [CrossRef] [PubMed]

55. Xiong, L.; Yan, W.; Zubia, E.; Zhou, Y.; Zhang, Y.; Duan, Q.; Narayan, M.; Xu, G. Quantitative proteomics and biochemical analyses reveal the role of endoplasmin in the regulation of the expression and secretion of $\mathrm{A}$ Disintegrin And Metalloproteinase 12. J. Proteom. 2018, 182, 34-44. [CrossRef] [PubMed]

56. Rauscher, B.; Heigwer, F.; Henkel, L.; Hielscher, T.; Voloshanenko, O.; Boutros, M. Toward an integrated map of genetic interactions in cancer cells. Mol. Syst. Biol. 2018, 14, e7656. [CrossRef] [PubMed]

57. Allen, E.L.; Ulanet, D.B.; Pirman, D.; Mahoney, C.E.; Coco, J.; Si, Y.; Chen, Y.; Huang, L.; Ren, J.; Choe, S.; et al. Differential Aspartate Usage Identifies a Subset of Cancer Cells Particularly Dependent on OGDH. Cell Rep. 2016, 17, 876-890. [CrossRef]

58. Sickmier, E.A.; Frato, K.E.; Shen, H.; Paranawithana, S.R.; Green, M.R.; Kielkopf, C.L. Structural Basis for Polypyrimidine Tract Recognition by the Essential Pre-mRNA Splicing Factor U2AF65. Mol. Cell 2006, 23, 49-59. [CrossRef]

59. Giannakis, M.; Hodis, E.; Jasmine Mu, X.; Yamauchi, M.; Rosenbluh, J.; Cibulskis, K.; Saksena, G.; Lawrence, M.S.; Qian, Z.R.; Nishihara, R.; et al. RNF43 is frequently mutated in colorectal and endometrial cancers. Nat. Genet. 2014, 46, 1264-1266. [CrossRef]

60. Barbieri, C.E.; Baca, S.C.; Lawrence, M.S.; Demichelis, F.; Blattner, M.; Theurillat, J.P.; White, T.A.; Stojanov, P.; Van Allen, E.; Stransky, N.; et al. Exome sequencing identifies recurrent SPOP, FOXA1 and MED12 mutations in prostate cancer. Nat. Genet. 2012, 44, 685-689. [CrossRef]

61. Champion-Arnaud, P.; Reed, R. The prespliceosome components SAP 49 and SAP 145 interact in a complex implicated in tethering U2 snRNP to the branch site. Genes Dev. 1994, 8, 1974-1983. [CrossRef] [PubMed]

62. Golas, M.M.; Sander, B.; Will, C.L.; Luhrmann, R.; Stark, H. Major conformational change in the complex SF3b upon integration into the spliceosomal U11/U12 di-snRNP as revealed by electron cryomicroscopy. Mol. Cell 2005, 17, 869-883. [CrossRef] [PubMed]

63. Tanaka, Y.; Ohta, A.; Terashima, K.; Sakamoto, H. Polycistronic expression and RNA-binding specificity of the C. elegans homologue of the spliceosome-associated protein SAP49. J. Biochem. 1997, 121, 739-745. [CrossRef] [PubMed]

64. Shen, Q.; Nam, S.W. SF3B4 as an early-stage diagnostic marker and driver of hepatocellular carcinoma. BMB Rep. 2018, 51, 57-58. [CrossRef] [PubMed]

65. Marques, F.; Tenney, J.; Duran, I.; Martin, J.; Nevarez, L.; Pogue, R.; Krakow, D.; Cohn, D.H.; Li, B. Altered mRNA Splicing, Chondrocyte Gene Expression and Abnormal Skeletal Development due to SF3B4 Mutations in Rodriguez Acrofacial Dysostosis. PLoS Genet. 2016, 12, e1006307. [CrossRef]

(C) 2020 by the authors. Licensee MDPI, Basel, Switzerland. This article is an open access article distributed under the terms and conditions of the Creative Commons Attribution (CC BY) license (http://creativecommons.org/licenses/by/4.0/). 